\title{
Health locus of control as a psychological factor in improving treatment results in adolescents with primary hypertension and diabetes
}

\begin{abstract}
BACKGROUND
The belief that an individual can influence and control the course of events is a factor which enables a person to overcome difficulties. Some studies, however, have questioned the universality of this statement. This study aims to investigate and explore the relationship between the self-health locus of control and the effectiveness of cooperation in the treatment process in adolescents with chronic diseases.
\end{abstract}

\section{PARTICIPANTS AND PROCEDURE}

One hundred and sixty-four adolescent patients suffering from chronic diseases (61 girls and 103 boys) ranging from 11 to 17 years old participated in the study. Eighty-seven had primary hypertension and 77 had type 1 diabetes. To investigate their sense of health control we used the Health Locus of Control Scale (HLC). Cooperation in the treatment process was assessed using a 4-item scale completed by a doctor.

\section{RESULTS}

Better results in the treatment were positively correlated with a better internal health locus of control. A negative correlation between the chance health locus of control and results in the treatment was found. Differences in the health locus of control proved to be dependent on gender, age and different clinical groups.

\section{CONCLUSIONS}

Health locus of control in patients with chronic diseases seems to be a crucial factor in determining the results of the treatment process in such patients.

\section{KEY WORDS}

adolescent; health locus of control; hypertension; cooperation in the treatment process; type 1 diabetes 


\section{BACKGROUND}

The concept of "your health in your hands" propagated by the World Health Organization reflects people's involvement and responsibility for their health. This concerns both healthy people and those with various medical conditions. Chronically ill adolescents often show limited involvement in the treatment or even deny their disease, while also being difficult to cooperate with, which is referred to as non-compliance. This problem is widespread even among people with serious diseases which require strict compliance with a medical regimen and regular medication (Rianthavorn \& Ettenger, 2005). Health attitudes are among the most important indications in health behaviour, including the sense of control over one's health (Del Castillo, Godoy-Izquierdo, Vázquez, \& Godoy, 2013). The health locus of control (HLOC) is a construct that describes the degree to which individuals are convinced that their health is controlled by internal or external factors. Persons with an internal health locus of control believe that their health is depended on their decisions, efforts and behaviours. If they do not succeed, they believe it is due to their own incorrect behaviours and lack of effort. Individuals with an external health locus of control are convinced that their health is controlled and depends on outside forces such as other powerful individuals or on chance and luck (Twenge, Zhang, \& Im, 2004). The possibility of making decisions transforms stress into a challenge instead of a threat, which can contribute to mitigating a negative stress response and give better outcomes (Santos-Ruiz et al., 2012).

\section{THE SENSE OF CONTROL OVER THE DISEASE}

The awareness of the disease is not automatically associated with greater responsibility over one's health and an active approach to treatment (Heszen \& Sęk, 2007). On the contrary, instilling health behaviour is a complex process, in which the patient, in order to achieve the desired health outcome, should specify a tangible objective (with the support of the doctor), such as regular blood pressure or sugar level measurements. Stating the objective and the intention to carry it out is not always sufficient for taking action. The patient should plan the method of implementing the planned activities, e.g. by setting an alarm on their mobile phone to remind them about the measurement. At each stage there are variables that could support or disturb the process (Łuszczyńska, 2004), e.g. it may happen that the school nurse's room is unavailable and the patient might decide not to take his/ her injections, which is a health- and life-threatening choice. Therefore, instilling health behaviour necessitates, among other things, precise determination of the conditions for carrying out the plan and over- coming the potential obstacles, e.g. if the time of the measurement falls during school hours, the patient can check the sugar level (or blood pressure) in the nurse's room after prior arrangements with the parents and the student. Arranging alternative methods of solving a problematic situation prevents patients from abandoning the planned activities and contributes to achieving the goal. It is important to evaluate the tasks at each stage and modify them depending on the patients' ability to complete them. Smith et al. (2013) suggest that intervening with patients should take into account a number of factors that will match the impact of the specific behaviour of the recipient.

There is evidence indicating that the internal locus of control has a beneficial effect on both the patient's approach to their health and the quality of their cooperation with doctors, including the treatment outcomes. Research conducted by Taher et al. (2015), who analysed the relationship between the health locus of control and cooperation in the treatment process, demonstrated that patients experienced fewer complications and achieved better treatment parameters. Furthermore, there are data available which demonstrate that the internal health locus of control has a favourable effect on the immune system, while lack of control, and helplessness, can prove to have the opposite effect (Ścigała, 2001). Being convinced about the lack of control over events can lead to learned helplessness (Mutlu, Balbag, \& Cerek, 2010).

The aforementioned study conclusions suggest that the control mechanism can function as a person's psychological resource which enables normal functioning and effective adaptation to events. Due to the above, the conclusions constitute a solid foundation for applying supporting, motivating and activating methods towards patients to increase their sense of control and take more responsibility over their lives.

\section{THE HEALTH LOCUS OF CONTROL IN CHILDREN}

Developing a sense of control depends on two conditions - the predictability of events and the so-called "ego" competences (Sęk, 2014). Both can be met for chronically ill children, as many aspects of the disease are predictable and can be controlled by the patient. Therefore, it is important for the patient to be aware of the course of the disease, its consequences and possible complications. Ljungman and Myrdal (1993) in their search for factors influencing the patient's cooperation in the therapy process considered, inter alia, the level of the patient's knowledge of the disease (the knowledge aspect). The researchers carried out their study among a group of adolescents with coeliac disease and concluded that the higher the level of knowledge on one's disease, the more effective
Health locus of control in adolescents with primary hypertension and diabetes 
Marta Anna

Biernacka,

Anna

JakubowskaWinecka the cooperation in the therapy process (Ljungman \& Myrdal, 1993). It is also of essence to observe the relationship between one's health behaviour and its effects (Sęk, 2007), e.g. whether the patient can see the cause-and-effect relationship between following the medical regimen, such as the diabetic diet, and their improved comfort and blood sugar test results. Data obtained from a study carried out among diabetic adolescents demonstrated that patients with a positive attitude towards their disease were more involved in the treatment process and presented with

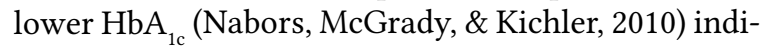
cators. The existence of this relationship is crucial for the consideration of the positive outcomes of therapy (Lahdenpera \& Kyngas, 2001).

The competence condition is met if the patient shows an ability to implement medical recommendations, e.g. is able to measure blood sugar levels and carry out insulin injections without assistance. The sense of control becomes internalised and reinforced when a child experiences situations in which he or she manages to achieve the planned goal.

In the natural process of cognitive development, as a result of, inter alia, interactions with the environment and gaining experience, the internalisation of control over events and the ability to self-regulate grow with age. Research on the locus of control shows that it is a developmental process governed by the same principles as cognitive development as described by Piaget (Carraccio, McCormic, \& Weller, 1987). According to Piaget's concept, children aged 11-12 gradually internalise their disease, which begins to be perceived as an internal psychophysical process. With age not only does the child's level of health cognition become higher (Bares \& Gelman, 2008), but also awareness of the disease process increases, together with the conviction that the process can be to a certain extent controlled and influenced by the appropriate behaviour (Altman \& Revenson, 1985).

Most studies on health locus of control as a factor related to adherence indicate a positive relationship between ability to control health and more positive adherence. The internal health locus of control contributes to the autonomy of one's actions and activity in general, and increases the sense of responsibility for one's health (Burkhart \& Rayens, 2005; Burker, Evon, Galanko, \& Egan, 2005). It seems that developing this aspect of personality is crucial both for healthy and chronically ill patients. Clinical practice shows that in the course of the disease and treatment patients are often faced with circumstances which make them believe that it is not their own actions that make them healthy but external factors. Patients are dependent on the healthcare system, and are often required to passively and completely follow the instructions and recommendations of the medical staff (medical imperialism) (Sheridan \& Radmacher, 1998).
Most current published research on the health locus of control concerns adult patients, while few studies have focused on children. In the context of the above considerations and a small number of studies that included children with chronic illness, an attempt was made to analyse the relationship between the health locus of control in chronically ill adolescents and the cooperation with the doctor and treatment outcomes, taking into account such variables as the type of chronic condition and the age and gender of the patient.

\section{PARTICIPANTS AND PROCEDURES}

\section{PARTICIPANTS}

The study population consisted of 164 adolescents (61 girls and 103 boys) diagnosed with type 1 diabetes and hypertension and aged from 11 to 17 years. The mean age of the patients was $M=15.02$ $(S D=1.75)$ years. The proportion of boys and girls to be approximately $2: 1$. Eighty-seven patients (53\%) were patients with primary hypertension and 77 patients $(47 \%)$ were patients suffering from type 1 diabetes.

The study was carried out by psychologists from the Department of Health Psychology of the Children's Memorial Health Institute in Warsaw in the period between 2007 and 2015. Patients treated in the diabetology and nephrology outpatient clinic who met the diagnostic criteria for diabetes and hypertension were invited to participate in the survey. The survey was conducted with each patient individually while waiting for an appointment or after a consultation with the doctor. In the case of children aged less than 16 , the consent to participate in the study was obtained from the children's parents after informing them about the purpose and procedure of the study. The survey involved the completion of a questionnaire by those surveyed, with a separate questionnaire completed by the doctor.

\section{PROCEDURES}

The health locus of control was analysed using the Health Locus of Control Scale (HLC) developed by G. S. Parcel and M. P. Meyer, with the Polish adaptation prepared by Z. Juczyński (2001).

The method made it possible to specify the expectations related to health control in three dimensions.

Internal HLC: is a personal convictions that people themselves can influence their health and control the course of their diseases with their behaviour.

External HLC: is a personal conviction that one's health is a result of other people's actions, in particular of the medical personnel. 
Chance HLC: is a personal conviction that one's health depends on random external factors, and the control of behaviour responsible for one's health is very limited.

In order to evaluate the degree of cooperation and the treatment outcomes, a 4-item questionnaire was prepared, to be completed by the doctors. The authors of the questionnaire decided that cooperation between the patient and the doctor would be evaluated on the basis of four dimensions (cf. Table 1). Replies were marked on a 5-level Likert scale, where 1 was interpreted as a low value and 5 as a high value for each of the analysed aspects of cooperation included in the questionnaire. The assessment was carried out by 6 doctors working at the Clinic of $\mathrm{Ne}$ phrology, Hypertension and Kidney Transplantation of the Children's Memorial Health Institute. All patients were under the continuous medical care of the doctors, so their assessments were not random.

\section{STATISTICAL METHODS}

The data were analysed using SPSS for Windows, version 19 . The association between the scores on the HLC and each aspect of the questionnaire for doctors was examined using Kendall's tau rank correlation. The relationships of HLC with demographic and cooperation in the treatment process with age and gender were evaluated using the Mann-Whitney $U$ test.

\section{RESULTS}

\section{DIFFERENCES IN HEALTH LOCUS OF CONTROL AND FOUR DIMENSIONS OF MEDICAL COOPERATION BETWEEN PATIENTS WITH HYPERTENSION AND DIABETES}

With a view to determining whether the type of the disease has an impact on personal convictions about health control and on particular dimensions of cooperation, two groups were compared: patients with hy- pertension and patients with diabetes. The analysis of the obtained results showed that the profile of diabetic and hypertensive patients was similar in terms of the health locus of control. Most of the patients with hypertension and diabetes were convinced that their behaviour could influence their health and that they were able to control the course of the disease (internal HLC). The patients in both groups obtained values close to maximum in this category (the maximum number of points in the internal HLC dimension is 6 points). The fact that the patients in their treatment process preferred to rely on themselves and be active in areas which would have an impact on their health instead of passively waiting for the medical personnel to take action was reflected in the low values obtained in the remaining dimensions, i.e. external and chance HLC. Furthermore, the analysis of the data showed a difference between the two groups of patients in the chance HLC dimension. The patients with hypertension, in statistical terms, were more convinced than diabetic patients that their health condition was independent of their actions and was a result of the influence of random external factors.

Statistically significant differences between the surveyed groups of patients were obtained for active participation in the therapeutic process, the doctor's satisfaction about the treatment and the treatment parameters. Hypertensive patients were characterised by greater involvement in their treatment in comparison with the diabetic patients; their treatment outcomes were better, and so was the level of the doctor's satisfaction with the cooperation. The level of knowledge of the disease was similar for both groups. The obtained correlations are presented in Table 2 and Figures 1 and 2.

\section{ASSOCIATION BETWEEN HEALTH LOCUS OF CONTROL AND COOPERATION IN THE TREATMENT PROCESS}

Using a non-parametric test, Kendall's tau rank correlation coefficients were calculated between the

Table 1

Questions concerning medical cooperation

\begin{tabular}{cc}
\hline \multicolumn{2}{c}{ 4-item questionnaire } \\
\hline $\begin{array}{c}\text { 1. Knowledge about the disease } \\
\text { 2. Patient activity in the treatment process }\end{array}$ & Patient knowledge about the disease is: \\
$\begin{array}{c}\text { 3. Doctor's satisfaction with cooperation } \\
\text { with the patient }\end{array}$ & Are you happy with the cooperation of the patient? \\
$\begin{array}{c}\text { 4. Current treatment } \\
\text { parameters }\end{array}$ & Bypertensive patients \\
\hline
\end{tabular}

Health locus of control in adolescents with primary hypertension and diabetes 
Table 2

Descriptive statistics for the HLC and various dimensions of cooperation in the treatment process in the samples with different diagnoses

\begin{tabular}{|c|c|c|c|c|c|c|c|c|}
\hline & & \multicolumn{3}{|c|}{$\begin{array}{l}\text { Health locus of control } \\
\qquad M(S D)\end{array}$} & \multicolumn{4}{|c|}{$\begin{array}{l}\text { Dimension of cooperation } \\
\qquad M(S D)\end{array}$} \\
\hline & & Internal & External & Chance & $\begin{array}{l}\text { Knowl- } \\
\text { edge }\end{array}$ & $\begin{array}{l}\text { Patient } \\
\text { activity }\end{array}$ & $\begin{array}{l}\text { Doctor's } \\
\text { satisfac- } \\
\text { tion }\end{array}$ & $\begin{array}{c}\text { Current } \\
\text { parame- } \\
\text { ters }\end{array}$ \\
\hline Hypertensive & $n=87$ & $5.79(0.46)$ & $2.36(1.88)$ & $2.44(1.06)$ & $3.45(0.94)$ & 3.49 (1.17) & $3.63(1.14)$ & 3.43 (1.19) \\
\hline Diabetes & $n=77$ & $5.57(0.67)$ & $2.18(1.78)$ & $1.65(0.79)$ & $3.53(0.85)$ & $3.04(1.05)$ & $3.08(1.13)$ & $2.99(1.24)$ \\
\hline$t$-Student & & & & $t=5.32^{*}$ & & $t=2.60$ & $t=3.11$ & $t=2.30$ \\
\hline
\end{tabular}

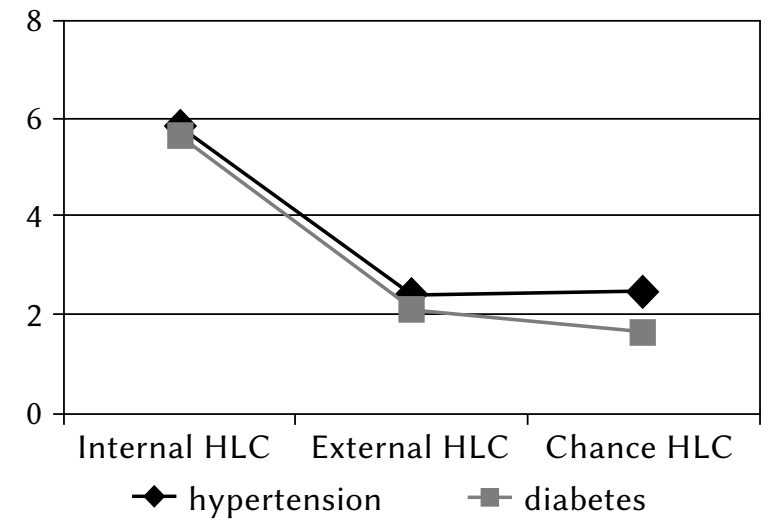

Figure 1. Differences in health locus of control between patients with hypertension and diabetes.

health locus of control and the evaluation of cooperation by the doctor obtained using the questionnaire. The analyses covered the entire group of respondents.

In the analysed group of adolescents, two major correlations between the variables were found. Internal HLC was positively correlated with the patient's activity $(\tau=0.14, p=.034)$ and the satisfaction of the doctor with the cooperation $(\tau=0.17, p=.030)$. However, external HLC was associated with a lower level of patient knowledge about the disease $(\tau=-0.13, p=.040)$.

\section{ASSOCIATION BETWEEN HEALTH LOCUS OF CONTROL AND COOPERATION IN THE TREATMENT PROCESS DEPENDENT ON GENDER}

The two dimensions of the sense of control over ones' health, i.e. internal and random, were associated with various gender-dependent aspects of cooperation in the therapeutic process. The patients' belief that their health depended on other people (external HLC) was manifested in a different way depending on gender. The external HLC in male patients was positively cor-

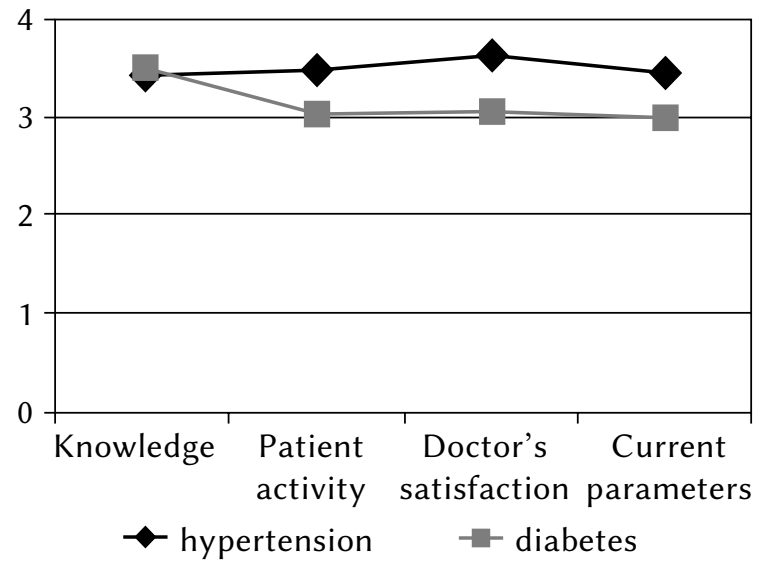

Figure 2. Differences in four dimensions of medical cooperation between patients with hypertension and diabetes.

related only with knowledge of the disease, while in the case of female patients, the correlation was also found with the treatment outcomes and the doctor's satisfaction with the cooperation. However, the conviction of the lack of control and the impact of random factors on health (chance HLC) turned out to be unfavourable for cooperation during the treatment process, as it was associated with lower activity and involvement among female patients, and a lower level of knowledge of the disease in the case of male patients. The obtained results are summarised in Table 3.

\section{ASSOCIATION BETWEEN HEALTH LOCUS OF CONTROL AND COOPERATION IN THE TREATMENT PROCESS DEPENDENT ON AGE}

The next step in the analysis involved studying the associations between the dimensions of health locus of control and the individual aspects of cooperation in the treatment process depending on the patient's age. The entire patient group was divided into an older group (aged 15-17) and a younger group (56 people aged 11-14). Contrary to expectations, the results did 
Table 3

Association between health locus of control and cooperation in the treatment process dependent on gender

\begin{tabular}{lcccc}
\hline HLC & Knowledge & Patient activity & Cooperation with patient & Treatment parameters \\
\hline Internal locus & & & \\
External locus & $\tau=0.16^{*}$ & $\tau=0.24^{*}$ & $\tau=0.24^{*}$ \\
Chance locus & $\tau=-0.23^{*}$ & $\tau=-0.23^{*}$ & & \\
\hline
\end{tabular}

Note. ${ }^{*} p<.05$

Table 4

Association between health locus of control and various dimensions of cooperation in the treatment process dependent on age

\begin{tabular}{|c|c|c|c|c|}
\hline HLC & Knowledge & Patient activity & Cooperation with patient & Treatment parameters \\
\hline Internal locus & $\tau=0.22^{*}$ & & $\tau=0.28^{*}$ & \\
\hline External locus & & & & $\tau=0.21^{*}$ \\
\hline Chance locus & & & & \\
\hline
\end{tabular}

Health locus of control in adolescents with primary hypertension and diabetes not confirm the assumption that the locus of control had been internalised with age. All the observed associations with the internal HLC dimension were present in the group of younger patients, while an association with the external HLC dimension was observed in the group of older patients. In the younger group the internal locus of HLC was positively associated with doctor's satisfaction with cooperation and patient knowledge about the disease. On the other hand, in the older group, the belief that health mainly depended on the doctor and other people was positively correlated with the result of treatment, glycated haemoglobin levels and blood pressure values (Table 4).

\section{ASSOCIATION BETWEEN HEALTH LOCUS OF CONTROL AND COOPERATION IN THE TREATMENT PROCESS DEPENDENT ON THE DISEASE}

A correlation analysis between the beliefs concerning HLC and the respective aspects of cooperation depending on the disease was carried out (Table 5). In the diabetes patient group, no significant correla- tions were established. In the group of hypertensive patients, the belief in their possibility to influence their health (internal HLC) was positively associated with the patient's activity, the doctor's satisfaction with cooperation with the patient, and good treatment parameters (the effects of treatment measured by blood pressure values). Young people characterised by a belief that their impact on their health is random (chance HLC), as observed by the doctors, had a better knowledge about their disease, but were not particularly active in the treatment process, and the doctor's satisfaction with cooperation with the patient was lower the higher was the result in terms of chance HLC. The external HLC dimension was not associated with any aspect of cooperation.

\section{DISCUSSION}

Belief in one's possibility to influence the course of the disease and treatment directs one's thoughts and activities to taking control over the disease and improving one's effectiveness in the course of treatment.

Despite a relatively large volume of research into the role of beliefs on the possibility to control health,

\section{Table 5}

Association between health locus of control and various dimensions of cooperation in the treatment process dependent on the disease

\begin{tabular}{lcccc}
\hline HLC & Knowledge & Patient activity & Cooperation with patient & Treatment parameters \\
\hline Internal locus & $\tau=0.21^{*}$ & $\tau=0.21^{*}$ & $\tau=0.19^{*}$ \\
External locus & & & \\
Chance locus & $\tau=0.19^{*}$ & $\tau=-0.22^{*}$ & $\tau=-0.23^{*}$ & \\
\hline
\end{tabular}

Note. ${ }^{*} p<.05$ 
Marta Anna

Biernacka,

Anna

JakubowskaWinecka the researchers rather infrequently attempt to evaluate how the health locus of control translates into the actual activities undertaken by the patients. Most known studies test the theoretical model or indicate the hypothetical relations between the health locus of control and other personality-related variables, such as the need for information about the disease, readiness to make decisions, assertiveness, the sense of one's effectiveness, etc. (Schwarzer, 1997). Gale, Batty, and Deary (2008), in a very large group of more than 14,000 subjects, analysed the correlation between the locus of control and such variables as health-promoting behaviour as part of a longitudinal study. Its authors demonstrated that adults, who as 10-year-old children were convinced of their impact on the surrounding reality (Internal Locus of Control), at the age of 30 were at a smaller risk of smoking cigarettes and obesity, and had a higher tendency to engage in regular physical activity, when compared with individuals characterised by their belief in a small impact on reality. The authors demonstrated the moderating role of control-related beliefs on the general condition of people, in association with their intelligence and educational levels.

\section{HEALTH-RELATED BELIEFS AND THE COURSE OF TREATMENT}

The results of our study point to several interesting relationships. Our expectations were that health-related beliefs could modify the patient's behaviour towards the disease and their attitude towards treatment. In terms of cooperation during treatment the internal HLC dimension proved more beneficial than the chance dimension. Internal HLC was associated with the patient's activity and their physician's satisfaction with cooperation. This can be explained by the notion that an active attitude of the patient is in line with the physician's expectations, which influences their satisfaction with treating the patient. On the other hand, the patients' belief that their health is controlled by other people (external HLC) decreased their involvement in health-promoting behaviour, such as seeking information about the disease. External HLC was associated with a low level of knowledge about the disease and course of treatment.

\section{HEALTH-RELATED BELIEFS} AND THE PATIENT'S GENDER

Our analyses indicate that health-related beliefs and their role in the process of coping with chronic diseases are related to the patient's gender: the external HLC and chance HLC types of beliefs manifested themselves differently in males and females. In girls, the external HLC dimension was associated with more effective results of cooperation than in the case of chance HLC. The female patients' belief that their health depends on other people (especially medical staff) was associated with better treatment results and higher satisfaction of doctors. Presumably, the more submissive attitude of female patients could result from the greater degree of dependence on external reinforcement and approval by the community (which might be connected with the social expectations for this gender). In girls, the personal conviction of a very small degree of control over behaviour responsible for their own health and the activity of chance factors were associated with their lower activity in the process of treatment. In the group of boys, the respective dimensions of the sense of health control were associated only with the knowledge about the disease. Braman and Gomez (2004) demonstrated that the tendency to place control in the "other" dimensions was a strong predictor of seeking information on the disease. Our study did not confirm this correlation. The belief that factors responsible for health were random was associated with weaker motivation and readiness to cooperate in treatment and poor knowledge about the disease. Our results indicated that patients who were convinced that the course of the disease did not depend on their actions did not attempt to take control over their health and did not take health-promoting actions, including searching for information on the disease and its treatment. A reverse relation was observed in the external HLC dimension. Patients convinced of the impact of other people on their health and course of treatment were characterised by a higher level of knowledge about the disease. No relevant associations between the internal locus of HLC and aspects of cooperation by gender were observed.

\section{HEALTH-RELATED BELIEFS AND PATIENT'S AGE}

Contrary to the hypothetical presumptions, the results of our studies did not confirm that the internalisation of control increased with age. The collected data clearly indicate that the belief that one's health is the result of the actions of other people increases with age. This discrepancy can be explained by the assumption that in the case of long-lasting diseases and attempts made over many years to improve one's condition, which do not always result in the intended effect, children can develop a presumption on the limitation of their competencies and the necessity to restrict their activities, and also helplessness, etc., which impede the natural developmental tendencies.

This explanation is supported by the following research result: in older adolescents external HLC was associated with better glycol haemoglobin indicators and blood pressure levels. This means that the level of their involvement in controlling their health does 
not change with age. However, an increase occurred in the level of subordination to people, on whom according to the patients - their health depended.

\section{HEALTH-RELATED BELIEFS AND PSYCHOLOGICAL CHARACTERISTICS OF THE DISEASE}

In our study the importance of health-related beliefs was significantly associated with the characteristics of the disease. While the results presented above referred to the whole group of studied adolescents, when it came to particular diseases, they proved significant only in relation to patients with hypertension. The fact that no such correlations were observed in diabetes patients should be interpreted as one stemming from the specificity of this disease. Despite the psychological situation of patients from the two groups being similar in many ways (all patients received continuing specialist care and were subject to ongoing treatment), the risks and inconveniences associated with the disease and its treatment were different. This was in spite of the fact that the groups of hypertensive patients and subjects with diabetes included patients with a severe disease course, as well as patients not facing a great threat to their lives at the present stage of treatment. From the psychological point of view, the treatment of diabetes is associated with greater discomfort and even pain (stabbing pain). Controlling one's lifestyle and maintaining a diet are more rigorous and burdensome for patients. Furthermore, greater control and influence by the parents is observed in this group than in the group of hypertensive patients. This can reinforce the withdrawn attitude of the patients and strengthen their beliefs of not being able to control the disease or its course by themselves. In general, we can assume that in the group of children and adolescents with hypertension the influence of individual health-related beliefs and the level of the patient's personal involvement play a greater role in the course of treatment.

This train of thought is corroborated by the sources. The classic study by Taylor (1984) demonstrated the significance of the sense of control in the case of breast cancer. Even when the actual influence of the patients on their health was small, the subjective belief in the possibility of such control improved the process of adapting to this life-threatening disease, and eventually led to coping with it. On the other hand, in situations where the course of disease is difficult to control, but the threat is low, more beneficial psychological effects might be associated with lower engagement in control.

The final conclusions do not warrant a statement that strong internal HLC is the most beneficial type of belief in the course of treatment. Bissiacchi, Cardolesi, Cappelari, Savadori, and Tarantino indicated that individuals with internal HLC often discontinued their treatment or manipulated drug doses to experience control over the disease. Lacroix and Assal (2000) believe that people with extremely internal HLC are more prone to display even risky behaviour in relation to the disease, as they find it impossible to give up control. According to previously cited studies by Gale, people with internal HLC were at greater risk of hypertension (evaluated on the basis of the self-description of the subjects).

\section{CONCLUSION AND IMPLICATIONS FOR PRACTICE}

We investigated the health locus of control as a determining factor in cooperation in the treatment process in adolescents with chronic disease. In conclusion, the obtained results confirm the correlation between individual beliefs concerning health control and the result of treatment in the group of adolescents with diabetes and hypertension. The significance of various health-related beliefs is complex. Our study shows that it depends on the patient's age, gender and situational factors, including those related to the nature of the disease. Consequently, internal HLC was of significance when it came to cooperation between the patient and the doctor, but only in the group of younger patients. External HLC can be positively associated with the treatment result in the group of girls. Moreover, the obtained results do not confirm the theoretical assumptions that chance HLC is associated with negative results of treatment.

In chronic disease it is essential to continue taking medication. Poor cooperation in the medical treatment leads to deterioration of well-being, complications of the disease, and even danger or loss of life. Health locus of control in children with hypertension and diabetes may be clinically significant and affect communication between doctors and patients and adherence to treatment. Health care professionals should be aware of the fact that patients differ in their health locus of control. Healthcare workers should also recognize the individual beliefs concerning health control to provide competent health promotion services, and ultimately improved health outcomes.

\section{LIMITATIONS}

However, some limitations of this study should be considered in future research. We investigated the association between health locus of control and cooperation in the treatment process. Our study is an initial report and was cross-sectional in nature, which does not permit any statements on causality. Firstly, it would be interesting to explore what other variables may affect the relationship between individual be-
Health locus of control in adolescents with primary hypertension and diabetes 
Marta Anna

Biernacka, Anna

JakubowskaWinecka liefs concerning health control and the result of the treatment. In paediatrics, family is the child's primary source of strength and support. Parents play a pivotal role in the development of their child's competences, health concept and responsibility for their own health. In future studies, it would be worthwhile to check whether different parental attitudes determine the observed relationship. Secondly, we do not have any specific information regarding the duration of the patient's illness. It also has to be considered whether the patient's self locus of control changes over time and depends on the number of years since diagnosis.

\section{RefERENCES}

Altman, D. G., \& Revenson, T. A. (1985). Children's understanding of health and illness concepts: a preventive health perspective. Journal of Primary Prevention, 6, 53-67.

Bares, C., \& Gelman, S. A. (2008). Knowledge of illness during childhood: Making distinctions between cancer and colds. International Journal of Behavioral Development, 32, 443-450.

Bissiacchi, P., Cardolesi, C., Cappelari, G., Savadori, G., \& Tarantino, V. L'aderenza del paziente alle cure: primi dati di una ricerca longitudinale $[\mathrm{Pa}-$ tient adherence to treatment: initial results from a longitudinal study]. Trentinosalute.net (Documenti per la salute 10), Cap. 11.

Braman, A. C., \& Gomez, R. G. (2004). Patient personality predicts preference for relationships with doctors. Personality and Individual Differences, 37, 815-826.

Burker, E. J., Evon, D. M., Galanko, J., \& Egan, T. (2005). Health locus of control predicts survival after lung transplant. Journal of Health Psychology, 10, 695-704.

Burkhart, P. V., \& Rayens, M. K. (2005). Self-concept and health locus of control: factors related to children's adherence to recommended asthma regimen. Pediatric Nursing, 31, 404-409.

Carraccio, C. L., McCormic, M. C., \& Weller, S. C. (1987). Chronic disease: Effect on health cognition and health locus of control. The Journal of Pediatrics, 110, 982-987.

Del Castillo, A., Godoy-Izquierdo, D., Vázquez, M. L., \& Godoy, J. F. (2013). Illness beliefs about hypertension among non-patients and healthy relatives of patients. Health, 5, 47-58. doi: 10.4236/ health.2013.54A007

Gale, C. R., Batty, G. D., \& Deary, I. J. (2008). Locus of control at age 10 years and health outcomes and behaviors at age 30 years: the British cohort study. Psychosomatic Medicine, 70, 397-403.

Heszen, I., \& Sęk, H. (2007). Psychologia zdrowia [Health Psychology]. Warszawa: Wydawnictwo Naukowe PWN.
Juczyński, Z. (2001). Narzędzia pomiaru w promocji i psychologii zdrowia [Measurement tools in promotion and health psychology]. Warszawa: Pracownia Testów Psychologicznych.

Lacroix, A., \& Assal, J. P. (2000). Therapeutic education of patients. New approaches to chronic illness. Paris: Editions Vigot.

Lahdenpera, T. S., \& Kyngas, H. A. (2001). Levels of compliance shown by hypertensive patients and their attitude toward their illness. Journal of $A d$ vanced Nursing, 34, 189-195.

Ljungman, G., \& Myrdal, U. (1993). Compliance in teenagers with coeliac disease - a Swedish follow-up study. Acta Pediatrica, 82, 235-238.

Łuszczyńska, A. (2004). Zmiana zachowań zdrowotnych. Dlaczego dobre chęci nie wystarczają [Changing health behavior. Why good intentions are not enough]. Gdańsk: Gdańskie Wydawnictwo Psychologiczne.

Mutlu, T., Balbag, Z., \& Cerek, F. (2010). The role of self-esteem, locus of control and big five personality traits in predicting hopelessness. Procedia Social and Behavioral Sciences, 9, 1788-1792.

Nabors, L., McGrady, M. E., \& Kichler, J. (2010). Children's attitudes toward their diabetes, locus of control, and HbA1c levels. The Journal of Developmental and Physical Disabilities, 22, 475-484.

Rianthavorn, P., \& Ettenger, R. B. (2005) Medication non-adherence in adolescent renal transplant recipient: A clinician's viewpoint. Paediatric Transplantation, 9, 398-407.

Santos-Ruiz, A., Garcia-Rios, M. C., Fernandez-Sanchez, J. C., Perez-Garcia, M., Muñoz-García, M. A., \& Peralta-Ramirez, M. I. (2012). Can decision-making skills affect responses to psychological stress in healthy women? Psychoneuroendocrinology, 37, 1912-1921.

Schwarzer, R. (1997). Poczucie własnej skuteczności w podejmowaniu i kontynuowaniu zachowań zdrowotnych. Dotychczasowe podejście terapeutyczne i nowy model [Self-Efficacy in the Adoption and Maintenance of Health Behaviors: Theoretical Approaches and a New Model]. In I. Heszen-Niejodek \& H. Sęk (eds.), Psychologia [Psychology] (pp. 175-205). Warszawa: PWN.

Sęk, H. (2007). Psychologia kliniczna [Clinical Psychology]. Warszawa: Wydawnictwo Naukowe PWN.

Sęk, H. (2014). Spoteczna psychologia kliniczna [Social Clinical Psychology]. Warszawa: Wydawnictwo Naukowe PWN.

Sheridan, C. L., \& Radmacher, S. A. (1998). Psychologia zdrowia. Wyzwanie dla biomedycznego modelu zdrowia [Health psychology: challenging the biomedical model]. Warszawa: Instytut Psychologii Zdrowia, Polskie Towarzystwo Psychologiczne. 
Smith, S. M., Bayliss, E. A., Mercer, S. W., Gunn, J., Vestergaard, M., Wyke, S., Salisbury, C., \& Fortin, M. (2013). How to design and evaluate interventions to improve outcomes for patients with multimorbidity. Journal of Comorbidity, 3, 10-17.

Ścigała, I. (2001). Psychoneuroimmunologia jako dziedzina współczesnej psychosomatyki [Psychoneuroimmunology as a contemporary psychosomatic discipline]. In L. Cierpiałkowska \& H. Sęk (eds.), Psychologia kliniczna i psychologia zdrowia [Clinical psychology and health psychology] (pp. 33-60). Poznań: Wydawnictwo Fundacji Humaniora.

Taher, M., Safavi Bayat, Z., Niromand Zandi, K., Ghasemi, E., Abredari, H., Karimy, M., \& Abedi, A. R. (2015). Correlation between compliance regimens with health locus of control in patients with hypertension. Medical Journal of the Islamic Republic of Iran, 29, 194.

Taylor, S. E. (1984). Przystosowanie do zagrażających wydarzeń [Adjustment to threatening events]. Nowiny Psychologiczne, 6-7, 15-38.

Twenge, J. M., Zhang, L., \& Im, C. (2004). It's beyond my control: a cross-temporal meta-analysis of increasing externality in locus of control, 19602002. Personality and Social Psychology Review, 8, 308-319. 